\title{
Modificación de atribuciones de causalidad: estudio de caso
}

Alejandra Viridiana Gutiérrez García y Cecilia Méndez Sánchez ${ }^{1}$

\section{Introducción}

Desafortunadamente, hoy en día y en diversos planteles escolares, es cada vez más común que los niños manifiesten reacciones de frustración y otras emociones negativas que culminan en crisis de llanto cuando éstos se enfrentan a equivocaciones o errores dentro de las diversas actividades académicas que tienen que resolver en su vida cotidiana. Vivimos en una sociedad cada vez más competitiva en donde se sobrevalora el éxito y se considera que no tener buenos resultados es sinónimo de fracaso.

Esta situación ha venido preocupando a docentes y padres de familia que se preguntan por una explicación lógica de las reacciones emocionales de sus hijos cuando se enfrentan al fracaso, por lo que solicitan también una forma en la que éstas sean evitadas o modificadas. Por esto mismo, el objetivo del presente trabajo es hacer evidente, mediante un estudio de caso

1 Universidad Autónoma de Aguascalientes. 
único, el papel que las atribuciones de causalidad juegan dentro de las consecuencias psicológicas en los niños ante el fracaso, así como la posible manera de realizar una intervención psicológica individual.

Ante situaciones de fracaso, los diferentes agentes de socialización con los que convive el niño otorgan explicaciones sobre el porqué de los resultados, por ejemplo: "porque no pusiste atención", "porque la actividad era muy difícil", "porque no eres listo", las cuales se denominan atribuciones de causalidad y son estudiadas por la denominada teoría atribucional, la cual señala que los individuos, ante cualquier acontecimiento, pero especialmente ante los negativos y sorpresivos, buscan explicar su ocurrencia, verbalizando atribuciones causales que tendrán un impacto en su cognición, sus emociones y su conducta (Pintrich y Schunk, 2006), mismas que les ayudarán a tomar un punto de referencia y a evaluar sus propias capacidades y su propio rendimiento.

Bajo el modelo atribucional de Weiner (2005), estas atribuciones se clasificarán en tres dimensiones causales: locus de control (localización de la causa: externa o interna), estabilidad (duración de la causa: estable e inestable), y el control (capacidad de modificación voluntaria por el sujeto: controlable o no controlable). Dependiendo de esta clasificación, se tendrán efectos diferenciales en las reacciones afectivas, cognitivas y/o conductuales.

En el caso de la estabilidad, se modificarán las expectativas y motivación en tareas posteriores o similares relacionadas con la perseverancia en la tarea -lo que se refiere a la motivación de logro (Alonso, 1984)-; con relación al locus de causalidad se tendrán emociones que afectarán la autoestima, y de acuerdo a la dimensión control, el efecto redundará en la responsabilidad con sentimientos de vergüenza o culpa (Weiner, 2005; Alonso, 1984; De la Torre y Godoy, 2002).

Weiner (2005) se inclina por una reeducación de las atribuciones hacia el esfuerzo, el cual cobra importancia al ser conceptualizado como una causa interna, controlable e inestable, por lo que las expectativas de logro en tareas posteriores se verán incrementadas, manteniendo un nivel adecuado de motivación y 
adquiriendo un estilo cognitivo que servirá para su afrontamiento de una forma más adaptativa. Esto se logrará, además, favoreciendo en los niños una visión más objetiva al atribuir sus resultados a causas más realistas, considerando también otras variables que pudieron incidir en el resultado y que más que el esfuerzo son la causa real del mismo. Sugiere también hacer un mayor énfasis en el proceso de ejecución de la tarea más que en el resultado, dando importancia también a aquello que sí está bajo su control a pesar de que la causa haya sido externa, es decir, al esfuerzo realizado y al intento por llevarla a cabo.

\section{Método}

\section{Participantes}

- Niño de 10 años de edad que cursa el quinto grado de primaria en el Colegio Bosques en Aguascalientes, México. Se incorporó a él hace aproximadamente un año. Su colegio anterior también es clasificado como de alta exigencia. Es de nivel socioeconómico alto, vive con sus padres y con su hermana mayor de 13 años de edad que estudia en la secundaria de la misma institución y cuyos padres califican como "excelente en Matemáticas". La problemática referida por los maestros fue "baja tolerancia a la frustración".

- Tres maestras del niño de la misma institución, de aproximadamente 40 años de edad. Dos de ellas están frente al grupo la mitad de la jornada escolar, respectivamente (Español e Inglés), y la tercera imparte el Taller de Matemáticas sólo dos sesiones de 45 minutos a la semana.

\section{Material}

- Entrevista individual semiestructurada con el niño para indagar reacciones emocionales, conductuales y cognitivas ante el fracaso; intensidad, frecuencia, duración y otras características de la conducta. Fase de evaluación. 
- Entrevista individual semiestructurada con las maestras para indagar sobre características de lo que ellos clasificaban como "baja tolerancia a la frustración", así como características observadas para corroborar los datos anteriores. Fase de evaluación.

- Actividades lúdicas de retos y desafíos cognitivos (cubo de madera, torre de Hanoi, juego "Cover your tracks", etcétera): situaciones simuladas para inducir al fracaso, observar sus reacciones y corroborar la información arrojada en la entrevista (fase de evaluación). Modificación de atribuciones causales ante el fracaso (fase de intervención).

- Ejercicios matemáticos de dificultad elevada: mismo objetivo anterior. Fase de evaluación e intervención.

- Registro de ocurrencia de las reacciones que se estaban observando. Se consideraron las siguientes: despeinarse, enojarse, tener un nudo en la garganta/ojos Ilorosos/llorar -ámbito afectivo-; ganas de iniciar la actividad, de mantenerse en ella y de terminarla, y la intensidad del esfuerzo realizado -aspectos conductuales-, además de la especificación cualitativa de las atribuciones causales -elementos cognitivos-. Fase de evaluación e intervención.

- Registro para las maestras de evaluación de los avances obtenidos (mantenimiento, disminución o incremento de las características en cuanto a intensidad, frecuencia y duración). Fase de intervención.

\section{Procedimiento}

Estudio de caso único con diseño $A B$, realizando una evaluación continua de las reacciones psicológicas consideradas en el niño y agregando un diseño pretest-postest para comparar las reacciones antes y después de la intervención.

Para la fase de evaluación se realizaron las entrevistas a las maestras en aproximadamente 15 minutos en días variables. A la par de ello, con previa autorización de los padres del niño, se llevaron a cabo sesiones individuales con él, de aproximadamente 30 minutos por 3 días consecutivos, cuyo objetivo era el 
establecimiento del rapport y la recopilación de información respecto a reacciones cognitivas (atribuciones de causalidad), afectivas (emociones) y motivacionales (persistencia, mantenimiento en la tarea e inicio de una nueva), ante situaciones de fracaso. Las actividades realizadas para el pretest fueron la Torre de Hanoi y los ejercicios de razonamiento matemático.

Para la fase de intervención se llevaron a cabo sesiones individuales con el niño una vez por semana, de aproximadamente 30 minutos de duración, cuyos objetivos específicos estaban orientados hacia la identificación del papel del pensamiento en las reacciones emocionales, enfatizar la importancia del esfuerzo y el favorecimiento de su visión objetiva de las causas que generaron el resultado ante una situación determinada. A lo largo del proceso se utilizó el elogio cuando las reacciones del niño en los tres ámbitos iban adquiriendo un estilo más adaptativo. Asimismo, se le dejaban tareas sencillas para casa, de reflexión y aplicación de lo visto, en una situación de fracaso presentada durante la semana. Además, a la octava sesión se otorgó a las maestras un registro para evaluar los avances o retrocesos tenidos con el niño en cuanto a sus reacciones psicológicas en situaciones de fracaso.

\section{Resultados}

Las maestras reportaron que el niño se frustraba en la clase de Matemáticas y comenzaba a llorar cuando se revisaba un tema nuevo, diciendo que "las matemáticas eran imposibles y muy difíciles". El niño reportó la presencia de "bloqueos" y "estrés" en sus clases de matemáticas, caracterizándolos por el hecho de "no poder pensar" y la aparición de ganas de llorar o algunas veces presentar llanto. Para solucionarlo, adoptó la idea de "sí puedo", con lo cual dijo disminuir el estrés referido y obtener el resultado deseado en las actividades.

Respecto a las reacciones cognitivas, especialmente las atribuciones orientadas a la capacidad y las orientadas a la dificultad de la tarea, dentro de la línea base tendían hacia su dismi- 
nución y en la fase de intervención lograron ser disminuidas de manera considerable. El niño comenzó a dar mayor importancia al proceso de realización de la tarea más que al resultado obtenido. Las atribuciones orientadas al esfuerzo se mantuvieron sin ocurrencia a lo largo del proceso.

En cuanto a las reacciones afectivas, despeinarse como síntoma de estrés, así como las ganas de llorar o el llanto, pasaron de manifestarse durante la línea base a mantenerse sin ocurrencia durante la intervención. El enojo presentó una dirección oscilatoria en su ocurrencia a lo largo del proceso.

En relación con las reacciones conductuales, durante la línea base, el niño pasó de mantenerse en las actividades realizadas a ya no hacerlo, pero durante la intervención regresó a este mantenimiento inicial. El esfuerzo logró un incremento en intensidad conforme a las sesiones de intervención, llegando a ser incluso mayor que el presentado en la línea base. En cuanto a la terminación de la tarea propuesta y el inicio de una nueva, durante la línea base existía una tendencia hacia la no ocurrencia, pero conforme a la intervención, hubo una aparición constante a lo largo de las sesiones.

No fue posible concluir la fase de intervención ni se realizó el postest del diseño planeado porque su madre solicitó el abandono de las sesiones, pues el niño dijo que ya no tenía ningún problema y por tanto no requería de la atención psicológica, presentando apatía, desinterés y renuencia para realizar las tareas solicitadas para casa. Asimismo, la maestra de Español reportó haber incluido una estrategia que le estaba funcionando dentro del salón de clases: cuando el niño no concluía un trabajo, dejaba que lo entregara al día siguiente; además, le explicaba el tema que iban a revisar antes que a sus compañeros, para que al enseñárselo al grupo, él ya lo supiera y así evitaba reacciones de llanto.

Las maestras, en el registro de evaluación de los avances, coincidieron en la disminución de las características afectivas en cuanto a frecuencia, intensidad y duración, a excepción del enojo, que refirieron que se mantuvo en frecuencia, pero disminuyó en intensidad y duración. Las atribuciones causales como 
"no le entiendo", "no sé", "es imposible", "está difícil", disminuyeron también en cuanto a las tres características de medición. La evaluación de los aspectos motivacionales no fue especificada.

\section{Discusión}

Se hace evidente lo que propone Weiner (2005) respecto a que las atribuciones tendrán un impacto en las reacciones afectivas, cognitivas y motivacionales de los sujetos. Éstas comenzaron a modificarse haciendo énfasis en el proceso de ejecución más que en el resultado, sugiriéndole que para obtener un resultado positivo, tenía que esforzarse e intentarlo de la mejor manera posible y, si a pesar de ello el resultado era negativo, entonces se daba más importancia a la realización de las acciones que sí estaban bajo su control y dominio. Por esta razón, las atribuciones orientadas al esfuerzo en los resultados no tuvieron ocurrencia, pues la causa real de la situación no había sido la falta de esfuerzo, ya que durante el proceso de ejecución se le guiaba para que éste lo realizara adecuadamente. Se espera que la verbalización de estas atribuciones se haga evidente ante situaciones de éxito. Con todo ello, se favoreció la visión objetiva de las causas reales que originan resultados negativos, trabajando por disminuir la ocurrencia de aquéllas orientadas hacia la capacidad y la dificultad de la tarea por ser causas externas, estables y no controlables, lo cual provocó entonces que las reacciones psicológicas, su afrontamiento y su motivación fueran más adaptativas.

Los resultados pudieron haber sido generalizados de una forma más adecuada si el proceso de intervención hubiera sido concluido, logrando mantener también los avances a lo largo del tiempo; sin embargo, existieron limitantes que influyeron en la deserción del programa, principalmente el desinterés del niño, al creer que ya no tenía ningún problema, lo cual probablemente fue ocasionado por la estrategia que empleó la maestra de Español, en donde reforzaba la evitación del fracaso, con lo que impedía que se manifestaran las crisis de Ilanto. De esta ma- 
nera, la evaluación de los avances de las reacciones afectivas otorgada por dicha maestra no es del todo fidedigna, pues no lo estaba enfrentando a situaciones de fracaso y sus reacciones reales no se hacían evidentes con ella.

Se sugiere que para estudios posteriores se considere el impacto que los maestros generan en las variables consideradas, ideando incluso formas de capacitarlos para lograr los avances de manera más efectiva y su generalización a otros contextos.

\section{Referencias}

Alonso, J. (1984). ¿Cómo conseguir que Juan realice su tarea? Algunas ideas generales sobre la motivación de logro y su modificación. Infancia y Aprendizaje, 26, 3-13.

De la Torre, R.C. y Godoy, A.A. (2002). Influencia de las atribuciones causales del profesor sobre el rendimiento de los alumnos. Psicothema, 14(2). Recuperado de http://www. psicothema.com.

Pintrich, P. y Schunk, D. (2006). Motivación en contextos educativos. Teoría, investigación y aplicaciones. Madrid: Pearson Educación.

Weiner, B. (2005). Motivation from an Attribution Perspective and the Social Psychology of Perceived Competence. En A. Elliot y C.S. Dweck (Eds.), Handbook of Motivation and Competence (73-84). Nueva York: Guilford. 